\title{
The Investigating Officer and the Investigation Manager
}

\author{
PETER MARTIN
}

\section{Introduction}

Serious crime investigations can be protracted, are usually complex and are often controversial. The circumstances of one crime differentiate it from another. The victim and location might be different, the modus operandi, or way in which the offence occurred, may also be different. Regardless of such differences the processes utilised in the major crime investigation can and usually do, follow a tried and true process.

Although as Sue Wilkinson identifies in her chapter (2010), there seems to be a limitless diversity of new and emerging crime types which confront and challenge contemporary police officers, the reality is that many of these 'new' types are innovative manifestations of old crimes using new technologies. For the majority of police officers this array of innovative crimes will be the domain of specialist investigators and high level task forces. Seldom, if ever, will the general duties officer on the street handle complex high level criminal investigations.

The uncertainties in serious crime are juxtaposed against a standard investigative process which is employed to move uncertainty or unknowns to the known investigative domain. It is the uncertainty that exists around crime issues that makes orientation of effort problematic from a strategic and operational perspective. Policing agencies have control over where resources are allocated, the optimum skill levels of their workforce, the strategic and operational approaches to respond to crime and the willingness to engage in partnerships. The challenge of employing a standard investigative methodology is to enable police agencies to bring the right resources, at the right time to the right investigative problem.

While the scale, nature and motivation of crime does change, there are many common aspects in terms of processes of investigations. The seriousness of 
the crime and the sophistication of that crime can make the degree of effort to ascertain the truth more critical and so too the resources which are allocated to the effort.

Further, the search for 'truth' occurs in an environment where much of the information crucial to a successful resolution is unknown. Ascertaining what occurred, the circumstances of how it occurred and who is liable at law takes place in environments where the political, media, community and internal 'authorising environments' are stakeholders in the outcomes. These stakeholders can bring tension and apply pressure to the investigation for both information and an expeditious outcome.

This chapter is written from the perspective of both the investigative officer and the officer managing the investigation. The policing of serious crime, as opposed to those that are less serious, can change the management of investigations. Not all investigations are the same. The scale and complexity of investigations or alternatively their level of community or political sensitivity, can lead to more significant management structures required to deal with this complexity or sensitivity. The senior investigator, rather than merely driving an investigation at the operational level and acting semi-autonomously, assumes more of a management role. This senior investigator not only sets the investigative priorities but assumes responsibility for human, physical and fiscal resource management. This can also mean that the now investigator/manager also assumes responsibility for managing the media and other peripheral but necessary functions such as political briefings.

This chapter covers two areas. First are the uncertainties pertinent to the investigative process itself, which I use to comment on the work of Smithson, as well as the chapters of Fargher, and Kebbell and colleagues. Second, I use the concept of the authorising environment to provide a focus for commenting on the chapter by Lawrence. A summary of these comments and suggestions for areas which would benefit from further research are provided in Table 1. But first I set the scene with the link between the investigation and the authorising environment.

\section{The link between the investigation and the authorising environment-the who, how, when, where and why in context}

Police officers are taught early in their training to apply their skills and ability to restore order in otherwise chaotic situations. The police role primarily is to enhance public safety, both perceived and real. In this way police officers 
respond to situations where they first, restore peace, second, ascertain what occurred and third, ascertain if an offence was committed. In cases where a breach of law has occurred, the police officer uses his/her discretion to determine whether it is in the 'public interest' to proceed with a prosecution or some other intervention.

Police are similarly taught that the aim of criminal investigation is to establish the 'who, how, when, where and why' of a matter subject to an investigation. These five framing questions have more to do with the arrival than the investigative journey. As important as it is to be able to get to the known dimension of each question, the process by which investigators arrive at this point is critical to a successful investigation. Criminal law and procedures and practices both internal to the police service and more broadly to the criminal justice system, provide the framework which guides the criminal investigation. Operating outside such frameworks can, at best, render evidence inadmissible or at worst, leave the investigator liable for an offence. In any event, this has the capacity to derail the prosecution of the wrongdoer and place the investigation in jeopardy. Therefore in the quest for certainty in dealing with serious crimes, the course that is adopted is one that is governed by rules, regulations, legislation and long established conventions. These are referred to by Mark Moore (1995) as the authorising environment.

As this description shows, it is not possible, or desirable, to disentangle the investigative process and the authorising environment. However I shall concentrate first on the investigative process and then on the authorising environment.

\section{Moving the investigation from the unknown domain to the known}

If we were to think about the known and unknown factors in a serious crime incident using a two by two matrix, as was done by Bammer et al. (2008, adapted from Kerwin, 1993), we would see that there were four permutations with one absolute known and three variations of unknowns (refer to Table 2). 
Table 2: The known/unknown investigative matrix

\begin{tabular}{|c|c|c|c|}
\hline & & \multicolumn{2}{|c|}{ META-LEVEL } \\
\hline & & Known & Unknown \\
\hline \multirow{4}{*}{$\begin{array}{l}\text { PRIMARY } \\
\text { LEVEL }\end{array}$} & Known & Known knowns & Unknown knowns \\
\hline & & & (tacit knowledge) \\
\hline & Unknown & Known unknowns & Unknown unknowns \\
\hline & & (conscious ignorance) & (meta-ignorance) \\
\hline
\end{tabular}

In the four quadrants or domains, the combinations can be expressed as:

Known-knowns - those matters for which the investigator is aware of the things that they know. From an investigative perspective these may be issues which are provable from hard evidence (physical evidence) or alternatively which can be inferred by provable facts (such as motivations for an offence gleaned through direct evidence of an offender).

Known-unknowns - The investigation usually focuses on what we know we don't know, otherwise described as investigative ignorance. Much of the investigation occurs in this domain.

Unknown-knowns - This situation can be described as tacit knowledge and applies to situations in which the investigator using intuition picks up on subtle cues in the investigation which may infer guilt or innocence.

Unknown-unknowns - This domain is sometimes described as meta-ignorance and is arguably the most difficult domain for the investigation.

The challenge is to move the investigation from the unknown domains, in whatever quadrant, to the known-knowns. The investigation needs to be mindful of testing the known-knowns to ensure that the investigation has not merely been self-serving in terms of its outcomes - involving many of the biases described in the chapter by Mark Kebbell, Damon Muller and Kirsty Martin (2010). Furthermore, presentation of the unknown will always be part of a 'solid' well-developed brief of evidence as it can demonstrate or assist with understanding the likelihood of achieving knowledge/opinion beyond reasonable doubt. Smithson (2008), in examining metaphors for 'uncertainty', identifies a common view that knowledge is power and ignorance is helplessness and impotence. While that might be so, from a criminal prosecutorial perspective it also shows objectivity and impartiality. Naturally, criminal investigations can be prone to the same extent of uncertainties as in other domains, such as the business world. In his chapter Neil Fargher (2010) identifies that if something as seemingly predictable as software development 'cannot run to time and budget, then how can an investigation into an unknown criminal?' 
If 'necessity is the mother of invention', then it could be argued that, in investigating serious crime terms, that uncertainty is the mother of innovation and inspiration for truth/fact finding. Uncertainty, apart from being a frustration to an investigator, can be a source of opportunity. Smithson (2008) argues that uncertainty can motivate people positively and negatively and that people find uses for it (uncertainty) and do not always want to rid themselves of it. So too is uncertainty a potential opportunity. It can create willingness in the investigative team to think outside of the obvious. To explore what is possible as opposed to what is perceived as likely.

Unlike the Hollywood depiction of the criminal investigation, serious crimes are not usually solved by a charismatic intelligent investigator operating in isolation. In fact, most serious investigations are a team effort involving many people with a broad skill set in a range of disciplines. Increasingly, in an effort to defeat uncertainty, multidisciplinary teams with broad membership are employed to leverage off each other's skills, knowledge, expertise and, importantly, legislative regimes. The multidisciplinary approach is helpful in terms of analysing information and data but what usually occurs in major crime investigations is that the investigative team is hopelessly overwhelmed with information. Fargher (2010) also discusses this phenomenon in business and suggests that there are software solutions. Within a serious crime construct however, information needs to be individually analysed by an intelligence analyst. While technology is useful in this domain there is no currently effective surrogate for the human approach. Another important point related to too much information is that, given the nature of the investigation, it is often not possible to stifle the flow. Fargher describes the challenge for business managers of managing and effectively tasking finite resources in an environment of competing priorities and where there are 'relatively unpredictable levels of demand or supply'. The same is true for the serious crime investigation.

\section{Intuition, heuristics and bias}

When the senior investigator assumes the senior management role he/she then becomes the driver for identifying both the relevant uncertainty that exists with respect to the investigation and the methodology to defeat that which is uncertain. Experience, knowledge, skill and intuition combine to assist the investigative direction. In the case of experience, knowledge and skill, these are learned behaviours refined by internal and external training opportunities and practical on-the-job experience. Intuition on the other hand is a much more difficult skill to identify and define. The expert investigator through intuition may instinctively pursue an investigative course that may seem speculative to the less experienced. 
Intuition is a highly prized resource in many fields of endeavour and it is equally highly prized in the management of serious crime. Length and breadth of criminal investigation experience are strong predictors of intuition, although not the only predictors. Individual perceptiveness is not solely determined by experience. To some degree, those individuals with high levels of intuition defy a complete scientific explanation, but their contribution to the investigation can be profound.

On the other hand, the real enemy of the investigator is the preconceived notion of 'truth'. When investigators take an erroneous belief that a situation occurred a particular way, and assume what the causal factors (motivation) were and who is likely to be responsible, then there can be an artificial conclusion before an investigation has run its course. In other words, generalisations are drawn based on aggregation of variables rather than compilation of the facts.

An investigation can be defeated and hopelessly compromised before it really begins, when investigators inexpertly and prematurely 'predict' the unknown factors. This is particularly the case where the evidence appears to fall within the known-known quadrant of certainty and can be accepted too willingly and not tested. The challenge for the principal investigator is to encourage objectivity at every stage of the investigation.

One way of maintaining objectivity is to document the process of the investigation. The major crime log not only details the outcomes of the inquiry but also the process employed and the evidence that was used or relied upon to inform the direction of the investigation. This is valuable both for its potential use in court proceedings and from the perspective of organisational and institutional learning. From a knowledge management perspective it is not just the arrival point that is important for the investigation but the journey of discovery.

In their chapter Kebbell and colleagues (2010) argue that there is a large amount of research which shows that that decision-making and informational processing abilities are not optimal because of contextual pressures which overwhelm cognitive ability and create bias. Intuition on the part of the investigator is important to the investigation, but can lead to bias. The challenge therefore is how to use intuition in such a way as to benefit the investigation and limit the potential for bias.

Bias is not only a relevant consideration for investigators themselves, but is also critical for assessing witnesses and others who have input into investigations. It is the natural human condition to want to make sense of uncertainty. Rumour and conjecture can be manifestations of an individual's attempts to provide certainty to uncertain situations. Either at a conscious or subconscious level the tendency is to defeat uncertainty by speculating or offering alternative 
scenarios which can bridge the divide to the unknown. This natural human condition can prove challenging for investigators. The overly 'helpful' witness who provides police with what they think will assist the investigation or the biased witness who is incapable or unwilling to take an objective view of the facts at hand, can significantly hamper an investigation. An extreme example is the case of Clare Werbeloff (otherwise colloquially referred to as the 'Chk-Chk Boom chick'), a 19 year old woman who sprang to international fame with her fictitious accounts of the shooting of a man in Sydney's Kings Cross in May 2009 (The Sunday Telegraph 2009).

\section{Public value and the authorising environment}

As indicated previously, the role of the investigation is to ascertain the truth of a situation. In doing so the investigation must also achieve public value. Public value from an investigative perspective involves the allocation of resources to give effect to the law and to achieve efficient outcomes. According to Moore (1995) public value is dependent upon operational capability, as well as what he calls an 'authorising environment'. The authorising environment is essentially the legislative and regulatory support for the investigation. But it can also have a downside through pressure to achieve results and demands for information about the investigation to be made public. This can serve to divert effort from the investigation to meet political and media needs. Such diversion of effort can also impact on the perception of impartiality or create the belief that a particular outcome is wanted. This is a highly undesirable situation that can run counter to the quest for truth. In terms of serious crime, the media are in a unique position. The media have the potential to exaggerate risks and demand from governments instant responses to theoretical threats. As Carmen Lawrence (2010) argues in her chapter '[t]he media exaggerate the risks we actually face and clamour for an instant response, especially from government, to threats that may never materialise'.

It is unsurprising that there is a discrepancy between the levels of actual crime and exaggerated perceptions of crime that both Lawrence (2010) and Robyn Attewell (2010) describe in their chapters. The media play a significant role in creating the context in which individuals asses risk to themselves, their families and the community in which they live. Lawrence argues that people behave as if their lives were becoming more and more dangerous and that they personalise rather than calculate objective risk, often exaggerating their vulnerabilitythis can then lead politicians and the media to exploit public anxiety about crime and cultivate public resentment towards those who offend. 
The role of politicians in the authorising environment has another dimension. It is important to have an appreciation of the intentions of the lawmakers who both drafted and enacted particular legislation that the investigation relies upon to extract its authority. The spirit and intent of legislation is critical to the investigator in the management of serious crime. The fundamental question when applying a particular offence provision is, what wrong was to be corrected by enacting this particular piece of legislation?

Moore's work (1995) on public value, not only highlights the importance of the authorising environment, but also provides focus on the term 'public'. In particular, the public interest test is an important consideration. Despite the fact that police may be working feverishly to uncover the truth of a matter and may have uncovered a set of circumstances where prosecution may occur, it may not be in the public interest to prosecute. This occurs to a lesser extent with serious crime than low-level matters. There can be a host of mitigating factors which may make prosecution unviable, including the minor or technical nature of the offence and the age or mental competence of the offender. In some serious crimes (e.g. euthanasia) defining public interest is difficult.

But the 'public interest' test in terms of prosecution is not the only impact from the public. The perceived wishes of the public in terms of serious crime are often strong drivers. In some cases they can be strongly influential and need to be managed, thereby further diverting the investigation effort towards public perception management. On the other hand, the mood of public sentiment might be against prosecution where the evidence would otherwise support such prosecution. An example is assisted suicide investigations.

There are many driving factors in investigations. From the perspective of the authorising environment, what is important is that there is certainty as to who the stakeholders are and that there is clarity in terms of their motivations. Importantly for the investigation, there needs to be a clear and unambiguous message from those who make up the 'authorising environment' in the Police Service to those managing and undertaking the investigation. One such significant message is the need to maintain objectivity by embracing and using uncertainty to investigative advantage.

\section{Conclusion: strategies to manage uncertainty}

All investigators seek to find certainty, yet investigations usually have varying degrees of uncertainty attached to them. Strategies that should be considered in attempting to provide clarity to that which is uncertain could include, but are not limited to, the following: 
1. at the commencement of the investigation an adherence to the philosophy of objectivity and to embrace uncertainty

2. a clear statement of intent with respect to the investigation (What is wanted to be achieved, when and by whom?)

3. a management and investigative structure that supports the investigation

4. a diversity of skills and talents which can objectively assess available information and weight it in terms of accuracy, objectivity and evidentiary worth

5. clarity concerning what the internal authorising environment expects from the investigation

6. an appreciation of the community, media and political interest in the investigation and an ability to use this interest to the benefit of the investigation

7. a carefully considered and well articulated investigative plan

8. leveraging off others, both internal and external, in an effort to finalise the investigation

9. objectively assessing the available evidence and making decisions to prosecute on an evidence basis, having regard for the criminal standard of proof and the public interest

10. the need to capture the learnings from the investigation to inform future practice in this area-combining knowledge management with continual improvement.

Almost all serious crime has elements of uncertainty. Even in the most seemingly clear-cut of matters, there are elements that are unknown where an investigative process needs to be employed to both elicit the circumstances of the matter and do this in such a way as not to render the evidence inadmissible in a court. Usually however, much to do with the serious crime is unknown to the investigator, at least initially.

The challenge is to respond to the crime in the first instance with sufficient resources and expertise so as to maximise the evidentiary value of any exhibits from the scene of the offence. The role of the principal investigator is to assemble sufficient resources (human, physical and intelligence) to enable a sustained effort for conducting an investigation having regard for the circumstances of the case.

Above all else, the investigator must be armed with objectivity. Arguably, objectivity and intuition are the investigator's greatest assets. Investigations can and do go awry. A significant risk point in most investigations is early in the investigatory life-cycle. A biased investigation which makes assumptions about the circumstances of the matter is unlikely to be made good with the 
passage of time. Time and effort are not, of themselves, enough to bring an investigation back from the brink of contamination. A professional and balanced investigation which has regard for the rule of law must be the starting point for any investigation and particularly those dealing with serious crime.

Rather than uncertainty being seen as a burden and something that confounds investigations, it should be construed as an opportunity: an opportunity to examine parallel scenarios which might explain motivations and behaviour; an opportunity to work with other agencies and those with expertise in other areas in a multidisciplinary context; and to advance the organisational knowledge that exists on such matters.

The views expressed in this chapter are those of the author and do not represent those of any agency including the Queensland Police Service or Queensland University of Technology. 
The Investigating Officer and the Investigation Manager

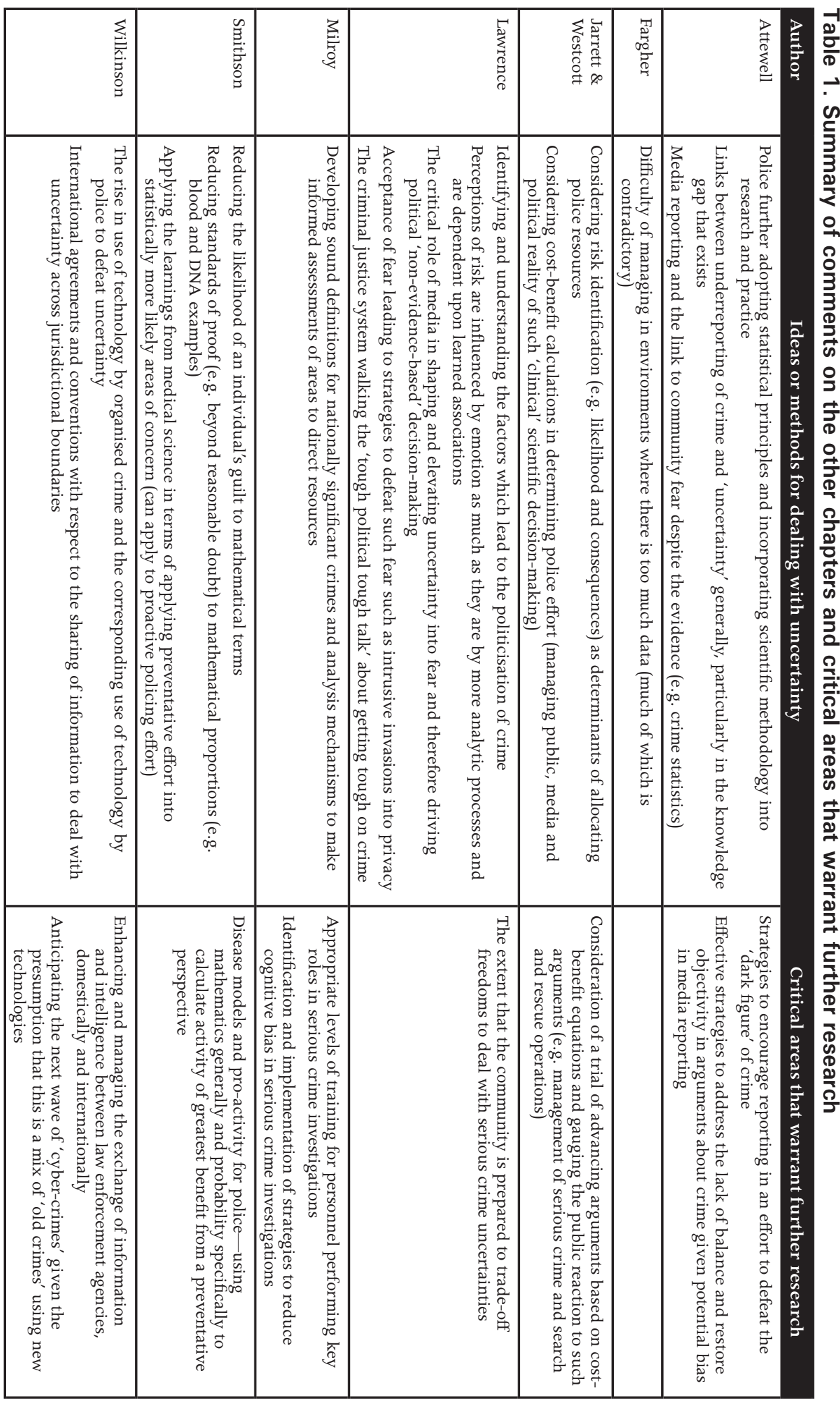


Dealing with Uncertainties in Policing Serious Crime

\section{References}

Attewell, R 2010, 'Can statistics help', in G Bammer (ed.), Dealing with uncertainties in policing serious crime, ANU E Press, Canberra.

Bammer, G, Smithson, M \& the Goolabri Group 2008, 'The nature of uncertainty', in G Bammer \& M Smithson (eds), Uncertainty and risk: multidisciplinary perspectives, Earthscan, London, pp. 289-303.

Fargher, N 2010, 'Business', in G Bammer (ed.), Dealing with uncertainties in policing serious crime, ANU E Press, Canberra.

Jarrett, R \& Westcott, M 2010, 'Quantitative risk', in G Bammer (ed.), Dealing with uncertainties in policing serious crime, ANU E Press, Canberra.

Kebbell, MR, Muller, DA \& Martin, K 2010, 'Understanding and managing bias', in G Bammer (ed.), Dealing with uncertainties in policing serious crime, ANU E Press, Canberra.

Kerwin, A 1993, 'None too solid: medical ignorance', Knowledge: creation, diffusion, utilisation, vol. 15, no. 2, pp. 166-185.

Lawrence, C 2010, 'Politics', in G Bammer (ed.), Dealing with uncertainties in policing serious crime, ANU E Press, Canberra.

Milroy, AM 2010, 'Law enforcement agencies which respond to nationally significant crime', in G Bammer (ed.), Dealing with uncertainties in policing serious crime, ANU E Press, Canberra.

Moore, M 1995, Creating public value: strategic management in government, Harvard University Press, Cambridge, MA.

Smithson, M 2008, 'The many faces and masks of uncertainty', in G Bammer \& M Smithson (eds), Uncertainty and risk: multidisciplinary perspectives, Earthscan, London, pp. 13-25.

Smithson, M 2010, 'Understanding uncertainty', in G Bammer (ed.), Dealing with uncertainties in policing serious crime, ANU E Press, Canberra.

The Sunday Telegraph 2009, 'Chk-Chk Boom chick Clare Werbeloff made up Sydney shooting account', <http://www.news.com.au/technology/story> (accessed 30 September 2009). 